\title{
FOTOSSÍNTESE, CONDUTÂNCIA ESTOMÁTICA E PRODUTIVIDADE DE CLONES DE Eucalyptus SOB DIFERENTES CONDIÇÕES EDAFOCLIMÁTICAS ${ }^{1}$
}

\author{
Marina Shinkai Gentil Otto ${ }^{2}$, Aline Regina Vergani ${ }^{3}$, Antônio Natal Gonçalves ${ }^{4}$, Arthur Vrechi ${ }^{3}$, Sérgio \\ Ricardo Silva ${ }^{3}$ José Luiz Stape ${ }^{5}$
}

\begin{abstract}
RESUMO - O objetivo deste trabalho foi avaliar a fotossíntese, condutância estomática e produtividade de clones de Eucalyptus em duas áreas distintas: uma no Município de Eunápolis, Sul da Bahia, com precipitação bem distribuída ao longo do ano (área úmida); e outra em Salto da Divisa, Leste de Minas Gerais, com precipitação concentrada nos meses quentes do ano (área seca). Foram estudados quatro clones, avaliando-se o crescimento, através do inventário das árvores; e as variáveis fotossintéticas, medidas com o aparelho Infrared Gas Analyser (IRGA). Dentro de cada área só houve diferença significativa entre clones na área úmida quanto à variável volume de madeira. A produtividade dos clones na área úmida foi 3,3 vezes superior à produtividade da área seca. $\mathrm{Na}$ área úmida, todos os clones diminuíram a condutância estomática com o aumento do déficit de pressão de vapor, com queda de $0,16 \mathrm{~mol} \mathrm{~m}^{2} \mathrm{~s}^{-1}$ para cada $1 \mathrm{kPa}$ de aumento no DPV e taxa fotossintética máxima

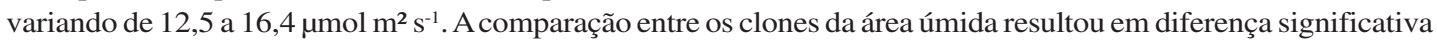
do clone $\mathrm{A}$, que apresentou fotossíntese máxima superior à dos demais. Na área seca não houve relação entre condutância estomática e DPV e não se observou diferença na fotossíntese entre os clones, que variou de 1,2 a $3,4 \mu \mathrm{mol} \mathrm{m} \mathrm{m}^{2} \mathrm{~s}^{-1}$. Verificou-se relação linear entre a fotossíntese máxima e a produtividade dos clones, evidenciando que a taxa fotossintética foi um dos fatores responsáveis pela maior produtividade do Eucalyptus na área úmida.
\end{abstract}

Palavras-chave: Eucalipto; Produtividade; Estresse hídrico.

\section{PHOTOSYNTHESIS, STOMATAL CONDUCTANCE AND PRODUCTIVITY OF Eucalyptus CLONES UNDER DIFFERENT SOIL AND CLIMATIC CONDITIONS}

\begin{abstract}
The objective of this study was to evaluate photosynthesis rate, stomatal conductance and productivity of Eucalyptus clones in two different sites; one in Eunápolis, southern Bahia with well distributed rainfall throughout the year (wet area) and another on Salto da Divisa, east of Minas Gerais, with rainfall concentrated over the hot months of the year (dry area). Four different clones were examined, measurements of plants growth were performed by means of inventory and the photosynthetic parameters were measured with IRGA (Infrared Gas Analyser). Within each area, there is difference between clones only in the wet area for the variable volume. The average productivity of the clones in the wet area was 3.3 times higher comparing to the dry area. All clones in wet area decreased stomatal conductance in response to increase in vapor pressure deficit, decreasing $0.16 \mathrm{~mol} \mathrm{~m}^{2} \mathrm{~s}^{-1}$ to each $1 \mathrm{kPa}$ increase in VPD and the maximum photosynthetic rate ranging from 12.5 to $16.4 \mu \mathrm{mol} \mathrm{m} \mathrm{m}^{-1}$ in this area. The comparison between clones within each area resulted in a significant difference in the wet area, with the clone A reaching maximum photosynthesis higher than others.
\end{abstract}

\footnotetext{
${ }^{1}$ Recebido em 26.11.2012 aceito para publicação em 12.05.2013.

${ }^{2}$ Programa de Pós-Graduação em Fisiologia e Bioquímica de Plantas na Universidade de São Paulo, USP, Brasil. E-mail: <groesalq@yahoo.com.br>.

${ }^{3}$ Veracel Celulose S/A. E-mail: <aline.vergani@ veracel.com.br>, <arthur.vrechi@ veracel.com.br $>$ e $<$ sergio.silva@ veracel.com.br>.

${ }^{4}$ Universidade de São Paulo, Escola Superior de Agricultura Luiz de Queiroz. E-mail: <natalgon@usp.br>.

${ }^{5}$ North Carolina State University, Department of Forestry and Environmental Resources. E-mail: <stape@ ncsfnc.cfr.ncsu.edu>.
} 
In the dry area, there was no correlation between stomatal conductance and VPD, and there was no difference in photosynthesis between the clones, ranging from 1.2 to $3.4 \mu \mathrm{mol} \mathrm{m} \mathrm{m}^{2} \mathrm{~s}^{-1}$. A linear relationship was observed between the maximum photosynthesis and clones productivity, suggesting that photosynthetic rate was one of the factors responsible for the increased Eucalyptus productivity of the wet area.

Keywords: Eucalypt; Productivity; Water stress.

\section{INTRODUÇÃO}

Nas últimas décadas, a área mundial cultivada com Eucalyptus tem aumentado consideravelmente. No Brasil, os plantios estão sendo realizados com grande frequência em áreas sujeitas a estresses hídricos, aumentando, assim, a necessidade de estratégias de seleção de materiais genéticos com maior tolerância às condições adversas de crescimento (ABRAF, 2011).

Historicamente, estudos sobre os processos fisiológicos de plantas em função de mudanças ambientais têm sido foco de muitas pesquisas. No âmbito da ecologia, o entendimento dessas interações é essencial em termos da tolerância de espécies a ambientes distintos. Em ambientes agrícolas e cultivos florestais, esses estudos podem auxiliar na seleção de genótipos, bem como na definição de estratégias de manejo das áreas cultivadas.

Embora milhões de hectares de eucalipto sejam intensivamente manejados para produção de madeira no mundo, pouco se sabe sobre os processos fisiológicos que controlam seu crescimento e como esses processos são regulados por fatores internos e externos (STAPE et al., 2004).

Além disso, uma das premissas básicas para a sustentabilidade de florestas plantadas está fundamentada na manutenção da produtividade e perpetuação do equilíbrio dinâmico entre entradas e saídas de energia e nutrientes (MORRIS; BENYON, 2005). Ou seja, o entendimento das interações genótipo e ambiente e seu efeito no crescimento é de fundamental importância para a manutenção da produtividade e sustentabilidade do meio ambiente.

Identificar quando a temperatura, a quantidade de luz, $\mathrm{CO}_{2}$, nutrientes e o suprimento de água são fatores limitantes para o crescimento é essencial para se entender como esses déficits podem ser amenizados. Nessas circunstâncias, é essencial intensificar as práticas de manejo para reduzir os fatores de estresse e desenvolver pesquisas, a fim de encontrar genótipos que apresentam maior resiliência perante fatores de estresse (WOOLHOUSE, 1984).

Nem sempre os ganhos esperados dentro dos programas de melhoramento genético têm sido compatíveis com os observados em campo. A esse fato tem se atribuído como causa principal a interação genótipo e ambiente, isto é, o material selecionado em um sítio não tem correspondido às expectativas quando se planta em outro local (KAGEYAMA, 1980). Além disso, variações nas regulações do potencial hídrico foliar, posição e inclinação das folhas e crescimento radicular reforçam a ideia de que a seleção de genótipos baseados somente em mensurações de crescimento volumétrico não são suficientes para a predição das respostas das árvores à seca (RYAN, 2011).

Inoue et al. (1979) destacaram a importância da fotossíntese nos programas de melhoramento florestal, enfocando a utilização desse parâmetro na identificação de comportamentos fisiológicos e como instrumento auxiliar nas decisões silviculturais.

Entender como ocorrem as influências do ambiente sobre o controle estomático tem sido foco central de estudos com fisiologia por causa da relação entre abertura estomática e aquisição de carbono pela planta (ADDINGTON et al., 2004). No entanto, os genótipos podem exibir níveis distintos de sensibilidade e taxa de resposta ao estresse hídrico, incluindo alteração da condutância estomática em relação ao déficit de pressão de vapor do ar, respostas fitoquímicas e de crescimento (MEDIAVILLA; ESCUDEIRO, 2004; HUAMAN, 2010).

Estudos realizados no campo diferem de estudos realizados no laboratório em razão, principalmente, da maior demanda evaporativa e maior variação climática em condições de campo. Ou seja, estudos cuja escala é a planta toda representam o melhor nível para integrar condições ambientais e respostas fisiológicas (GRANIER; TARDIEU, 1998; LARCHEVEQUE et al., 2011; RYAN, 2011).

Revista Árvore, Viçosa-MG, v.36, v.37, n.3, p.431-439, 2013 
Além de ser espécie de grande importância para a economia do Brasil e do mundo, o Eucalyptus é o segundo gênero florestal, depois do gênero Populus, com sequenciamento genômico funcional detalhado, destacando-se a importância de estudar as interações genótipo-ambiente dessa espécie.

Nesse sentido, torna-se evidente a necessidade de avançar o conhecimento sobre os processos fisiológicos acionados pelas plantas de eucalipto em diferentes condições de disponibilidade hídrica. O objetivo deste trabalho foi avaliar a taxa fotossintética e a condutância estomática de clones de eucalipto em duas áreas com condições edafoclimáticas distintas e integrar essas informações com a produtividade dos plantios em condições de campo.

\section{MATERIAL E MÉTODOS}

Foram implantados dois experimentos em áreas comerciais da empresa Veracel Celulose S/A. O primeiro experimento, denominado área úmida, localizado no Município de Eunápolis ( $16^{\circ} 22^{\prime} 40^{\prime \prime} \mathrm{S}, 39^{\circ} 34^{\prime} 48^{\prime \prime} \mathrm{W}$ ), no Sul do Estado da Bahia. O segundo experimento, denominado área seca, localizado no Município de Salto da Divisa (16 00' 10' S, 39 56' 49' W), a Leste do Estado de Minas Gerais. A Figura 1 apresenta a localização dos dois experimentos.

De acordo com a classificação de Köppen (1928), o clima da área úmida é do tipo Af (tropical úmido), com precipitação anual de 1.250 mm e temperatura média anual de $24^{\circ} \mathrm{C}$. Já a área seca apresenta clima Aw (clima tropical com estação seca de inverno), com precipitação média de $850 \mathrm{~mm} /$ ano e temperatura média anual de $25^{\circ} \mathrm{C}$.

Em novembro de 2008 foi instalado, em cada área, um experimento no delineamento experimental em blocos ao acaso, com quatro clones de Eucalyptus (clones A, B, C e D) e cinco repetições. A área útil das parcelas foi composta de 16 plantas (quatro linhas com quatro plantas) em espaçamento de 3 x $3 \mathrm{~m}$ ( $9 \mathrm{~m}^{2} /$ planta).

Os dados climáticos foram obtidos de duas estações meteorológicas, pertencentes à empresa Veracel Celulose S.A., localizadas próximas das áreas de estudo. O balanço hídrico foi calculado segundo o método de Thornthwaite e Matter (1955), utilizando planilhas eletrônicas conforme Rolim et al. (1998).

Em outubro de 2010, aos 23 meses de idade da floresta foram realizadas medições de fotossíntese, condutância estomática e déficit de pressão de vapor

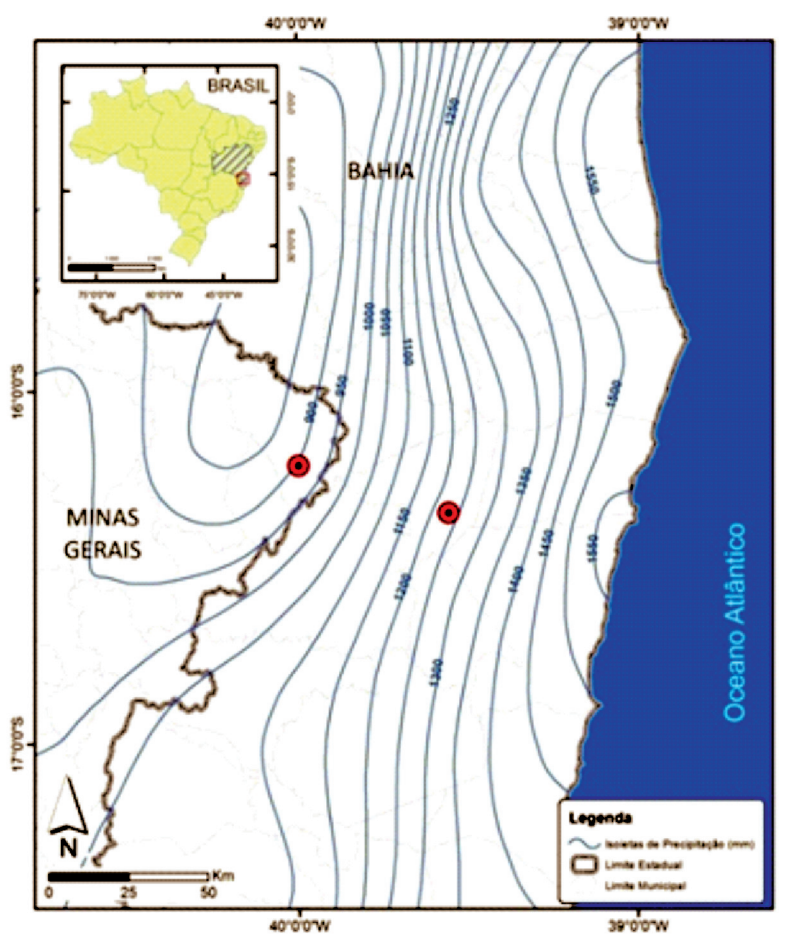

Figura 1 - Localização das áreas úmida e seca associadas com as isoietas históricas de precipitação.

Figure 1-Localization of wet and dry areas associated with the historical rainfall isohyets.

utilizando o aparelho IRGA (Infrared Gas Analyser, modelo Licor 6400). A definição do delineamento levou em consideração as possíveis variações entre árvores e do horário de medição. Dessa forma, todas as medições foram realizadas na segunda porção superior da copa, já que é a posição que apresenta maior capacidade fotossintética (MARRICHI, 2009).

As medições de fotossíntese máxima (Amax) foram realizadas em três árvores de cada clone, sendo cada campanha composta de um dia amostral para cada clone. Para cada árvore avaliada, foram selecionados dois galhos e duas folhas para cada galho, totalizando 12 repetições por tratamento. Essas medições foram realizadas no período das $8 \mathrm{~h}$ às $10 \mathrm{~h}$ da manhã, para garantir menores valores de déficit de pressão de vapor (DPV) e máxima abertura estomática. As avaliações foram realizadas alternandose as árvores a cada galho para garantir menor variação no horário de medição entre as posições da árvore.

Após as medições da fotossíntese máxima, as medições continuavam sendo efetuadas nos mesmos galhos e mesmas folhas, mas somente em duas árvores 
de cada clone, das $10 \mathrm{~h}$ da manhã até as $15 \mathrm{~h}$ da tarde. Desse modo, foi possível obter a relação da taxa fotossintética diária com as variações de DPV ao longo do dia.

Para avaliação da produtividade dos clones, foram realizadas medições da altura $(\mathrm{H})$ e diâmetro à altura do peito (DAP) em todas as árvores da parcela útil e feito o cálculo do volume (V), através da seguinte equação: $\mathrm{V}=\operatorname{Exp}(-10,0954+1,7907 * \mathrm{LN}(\mathrm{DAP})+$ $1,1306 * \mathrm{LN}(\mathrm{H}))$ (dados não publicados).

Para as variáveis DAP, $\mathrm{H}, \mathrm{V}$ e Amax foram realizadas análises de variância (ANOVA) e, quando o teste $\mathrm{F}$ apresentou significância $(P<0,10)$, compararam-se as médias pelo teste de Tukey no nível de significância de 0,05. Nesse caso, considerou-se o delineamento experimental em blocos ao acaso, no esquema fatorial 4 x 2 (quatro clones e duas áreas). Realizou-se a análise de regressão tendo condutância estomática (gs) e DPV como variável dependente, para avaliar a sensibilidade dos clones ao DPV. A regressão linear também foi utilizada para verificar a relação entre fotossíntese máxima e produtividade dos clones.

\section{RESULTADOS}

\section{Condições Climáticas}

Foi realizado o cálculo do balanço hídrico normal desde o plantio até a época das avaliações para as duas áreas avaliadas (Figura 2). Na área úmida, a pluviosidade acumulada foi de $2.909 \mathrm{~mm}$, sendo bem distribuída ao longo do ano, com precipitação média de 12 dias por mês e um excedente hídrico de $723 \mathrm{~mm}$ no final do período. Já na região seca a pluviosidade total foi de $1.454 \mathrm{~mm}$, com precipitação média de sete dias por mês e um déficit hídrico de $354 \mathrm{~mm}$.

$\mathrm{Na}$ área úmida, a temperatura média foi de $23^{\circ} \mathrm{C}$, com a média das máximas de $26^{\circ} \mathrm{C}$ e média das mínimas de $19^{\circ} \mathrm{C}$, enquanto na área seca as temperaturas média, máxima média e mínima média foram de $24^{\circ} \mathrm{C}, 27^{\circ} \mathrm{C}$ e $21^{\circ} \mathrm{C}$, respectivamente.

Durante todo o período, a radiação global média diária foi de $16 \mathrm{MJ} \mathrm{m}^{-2} \mathrm{dia}^{-1}$ na área úmida e $18 \mathrm{MJ} \mathrm{m}^{-2}$ dia $^{-1}$ na área seca, e em ambas as regiões a quantidade de horas-luz diárias atingiu uma média de 12,5 horasluz.

\section{Produtividade dos clones}

Dentro de cada área avaliada não houve diferenças significativas entre os clones quanto ao DAP e H, assim como V na área seca. Ou seja, de todas as variáveis de crescimento avaliadas, somente houve diferença de $\mathrm{V}$ entre os clones da área úmida. Nessa área, o clone $\mathrm{B}$ apresentou maior $\mathrm{V}$ do que os clones $\mathrm{A}$ e $\mathrm{D}$, e todos foram semelhantes ao clone C (Tabela 1).

Com relação à comparação entre as duas áreas avaliadas, houve diferença significativa dos valores médios de DAP, $\mathrm{H}$ e V de todos os clones entre as duas áreas. Os clones da área úmida apresentaram valores médios de $\mathrm{H}$ e V bastante superiores aos valores médios obtidos na área seca (Tabela 1). Na área úmida, os valores de DAP, $\mathrm{H}$ e V foram, respectivamente, 1,$1 ; 2$; e 3,3 vezes maiores do que os obtidos na área seca.

\section{Resposta da condutância estomática em relação ao DPV}

Todos os clones tiveram redução linear da condutância estomática (gs) com o aumento do déficit de pressão de vapor, na área úmida (Figura 3A). Já na área de clima seco não houve relação entre gs e DPV, e os clones mantiveram seus estômatos praticamente fechados ao longo do período avaliado (Figura 3B). Observou-se que, para o mesmo valor de DPV da área úmida, o valor da condutância estomática da área seca foi menor.

\section{Fotossíntese e produtividade dos clones}

Houve diferença significativa entre as médias de fotossíntese máxima quando comparadas com as duas áreas analisadas. A taxa fotossintética máxima atingida pelos quatro clones na área úmida variou de 12,5 a $16,4 \mu \mathrm{mol} \mathrm{m} \mathrm{m}^{2} \mathrm{~s}^{-1}$. Na área seca, a taxa fotossintética máxima variou de 1,2 a $3,4 \mu \mathrm{mol} \mathrm{m} \mathrm{m}^{2} \mathrm{~s}^{-1}$ (Tabela 1).

A comparação entre os clones dentro de cada área isoladamente resultou em diferença significativa na área úmida, com o clone A apresentando Amax superior ao dos demais, enquanto na área seca não foi observada diferença entre os clones.

Observou-se relação linear direta entre a fotossíntese média diária e a produtividade dos clones (Figura 4), evidenciando que a taxa fotossintética foi um dos fatores responsáveis pela maior produtividade da área úmida. 

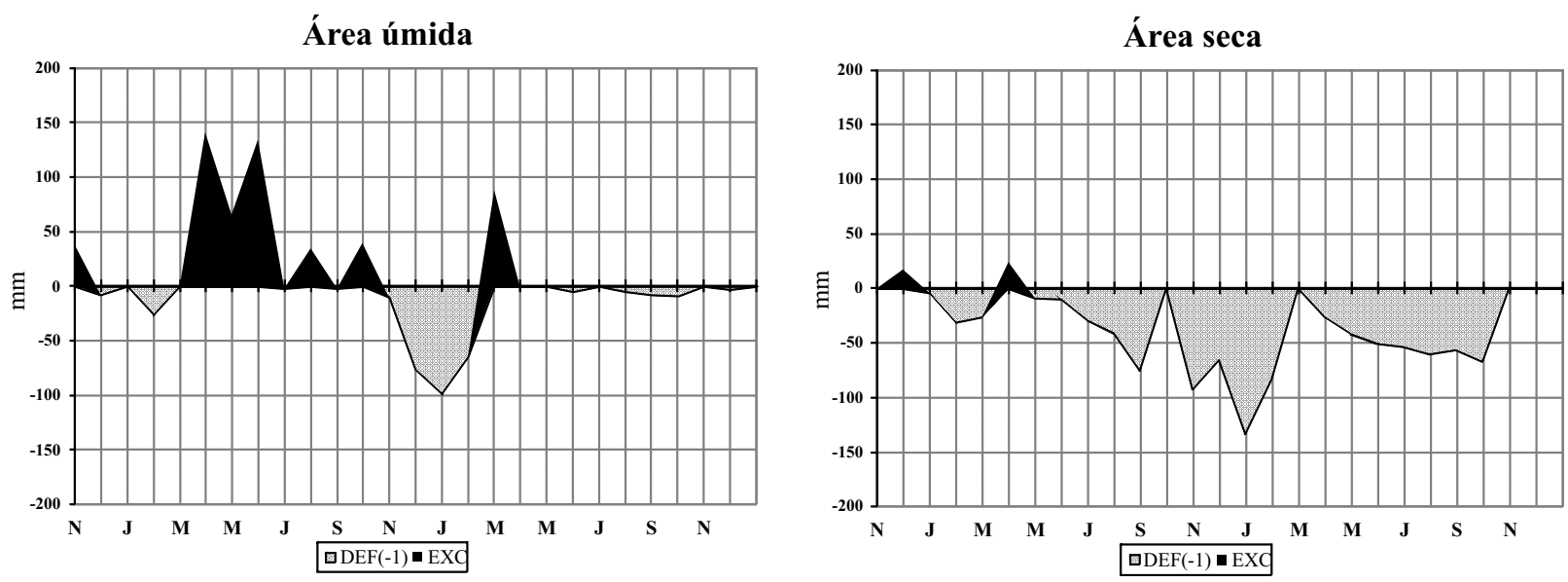

Figura 2 - Balanço hídrico mensal das áreas úmida e seca.

Figure 2-Monthly water balance of wet and dry areas.

Tabela 1 - Comparação entre diâmetro à altura do peito (DAP) médio, altura (H), volume (V) e fotossíntese máxima (Amax) nas áreas úmida e seca dos clones A, B, C e D aos 23 meses de idade.

Table 1 - DHB average, High (H), volume $(V)$ and maximum photosynthetic rates (Amax) in wet and dry areas of clones $A, B, C$ and $D$ with 23 months of age.

\begin{tabular}{|c|c|c|c|c|c|c|c|c|}
\hline \multirow{2}{*}{ Clones } & \multicolumn{2}{|c|}{ DAP } & \multicolumn{2}{|c|}{$\mathrm{H}$} & \multicolumn{2}{|c|}{ V } & \multicolumn{2}{|c|}{$A \max$} \\
\hline & Úmida & Seca & Úmida & Seca & Úmida & Seca & Úmida & Seca \\
\hline & \multicolumn{2}{|c|}{$\mathrm{cm}-$} & \multicolumn{2}{|c|}{$\mathrm{m}-$} & \multicolumn{2}{|c|}{$-\mathrm{m}^{3} \mathrm{ha}^{-1} \longrightarrow$} & \multicolumn{2}{|c|}{$-\mu \mathrm{mol} \mathrm{m} \mathrm{m}^{2} \mathrm{~s}^{-1}$} \\
\hline $\mathbf{A}$ & $12,4 \mathrm{a}$ & $11,3 \mathrm{a}$ & $16,3 \mathrm{a}$ & $8,0 \mathrm{a}$ & $98,1 \mathrm{~b}$ & $31,3 \mathrm{a}$ & $16,39 a$ & $1,19 \mathrm{a}$ \\
\hline B & $13,0 \mathrm{a}$ & $11,8 \mathrm{a}$ & $17,6 a$ & $8,6 a$ & $120,3 \mathrm{a}$ & $36,4 a$ & $13,29 b$ & $3,38 \mathrm{a}$ \\
\hline C & $12,5 \mathrm{a}$ & $11,4 \mathrm{a}$ & $16,9 a$ & $8,4 \mathrm{a}$ & $109,4 \mathrm{ab}$ & $33,3 \mathrm{a}$ & $12,49 b$ & $3,14 \mathrm{a}$ \\
\hline D & $12,6 \mathrm{a}$ & $10,6 a$ & $16,8 \mathrm{a}$ & $8,2 \mathrm{a}$ & $105,4 \mathrm{~b}$ & $30,2 \mathrm{a}$ & $13,56 \mathrm{~b}$ & $3,14 \mathrm{a}$ \\
\hline Média & $12,6 \mathrm{~A}$ & $11,3 \mathrm{~B}$ & $16,9 \mathrm{~A}$ & $8,3 \mathrm{~B}$ & $108,3 \mathrm{~A}$ & $32,8 \mathrm{~B}$ & $13,93 \mathrm{~A}$ & $2,71 \mathrm{~B}$ \\
\hline $\boldsymbol{P}_{\text {clones }}$ & \multicolumn{2}{|c|}{0,3015} & \multicolumn{2}{|c|}{0,0235} & \multicolumn{2}{|c|}{0,0020} & \multicolumn{2}{|c|}{0,0290} \\
\hline $\boldsymbol{P}_{\text {áreas }}$ & \multicolumn{2}{|c|}{0,0002} & \multicolumn{2}{|c|}{0,0001} & \multicolumn{2}{|c|}{0,0001} & \multicolumn{2}{|c|}{0,0001} \\
\hline $\boldsymbol{P}_{\text {clones x áreas }}$ & \multicolumn{2}{|c|}{0,7090} & \multicolumn{2}{|c|}{0,6599} & \multicolumn{2}{|c|}{0,1101} & \multicolumn{2}{|c|}{0,0002} \\
\hline
\end{tabular}

*P é a probabilidade calculada pelo teste F. Quando $\mathrm{P}<0,1$, as médias são comparadas pelo teste de Tukey. Médias seguidas por letras minúsculas distintas na coluna e letras maiúsculas distintas na linha (para uma mesma variável) diferem estatisticamente pelo teste de Tukey $(\mathrm{P}<0,05)$.

\section{DISCUSSÃO}

Segundo Floss (2004), para o adequado estabelecimento de cultivos agrícolas e florestais a distribuição mensal da precipitação é tão importante quanto a precipitação anual, já que a água é necessária durante todo o desenvolvimento da planta e é um dos fatores determinantes da produtividade. Sette et al. (2010) observaram que o período de máximo crescimento do tronco de árvores de Eucalyptus grandis estava relacionado com os altos níveis de precipitação, à disponibilidade de água no solo e à quantidade de horas de luz do dia. Dessa forma, as diferenças de produtividade encontradas entre as duas áreas evidenciaram que as condições climáticas, de temperatura, precipitação e radiação da área úmida foram mais favoráveis ao crescimento de todos os clones (Tabela 1).

Esses dados estão de acordo com de estudos que mostram a importância do aumento da disponibilidade de água para o crescimento do eucalipto. Em um estudo na Austrália com Eucalyptus globulus aos 10 anos de idade, houve incremento médio anual em volume 

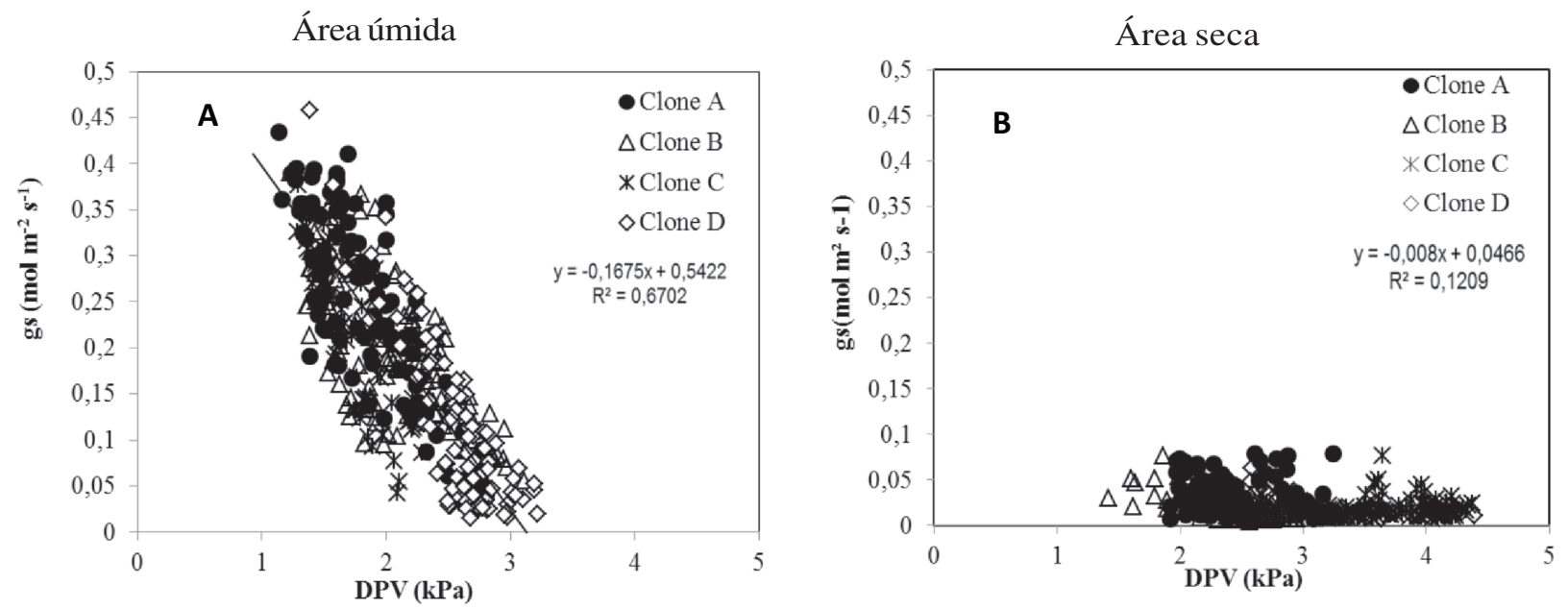

Figura 3 - Regressão linear relacionando a condutância estomática (gs) com o déficit de pressão de vapor (DPV) dos clones A, B, C e D na área úmida (A) e na área seca (B) aos 23 meses de idade.

Figure 3 - Linear regression, relating of stomatal conductance with vapor pressure deficit in $A, B, C$ and $D$ clones in wet (A) and dry area (B) with 23 months of age.

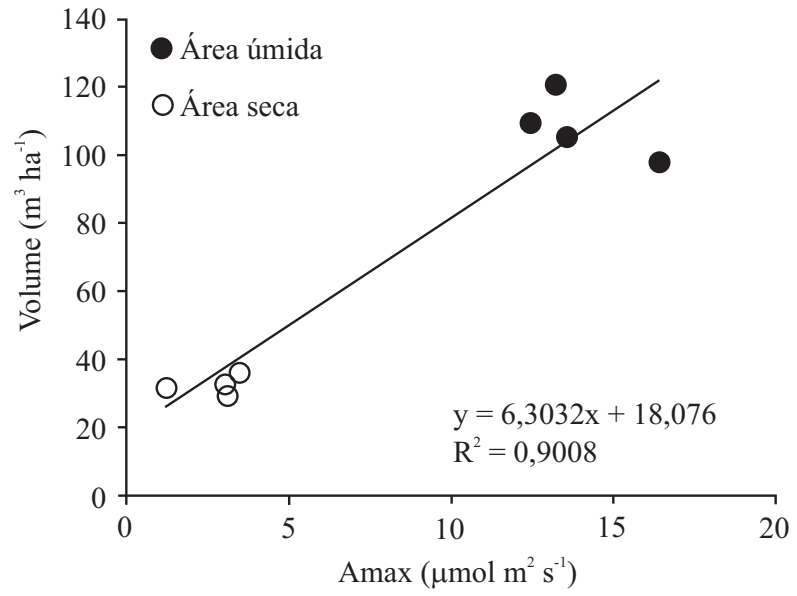

Figura 4 - Relação entre crescimento e fotossíntese média diária aos 23 meses de idade, nas áreas de clima úmido e seco.

Figure 4-Relationship between growth and daily photosynthesis average with 23 months of age in wet and dry areas.

cerca de $71 \%$ quando a precipitação aumentou de 600 para $1.300 \mathrm{~mm}$ ano $^{-1}$. Aumento de $100 \mathrm{~mm}$ na precipitação provocou incremento em torno de $4 \mathrm{~m}^{3} \mathrm{ha}^{-1} \mathrm{em}$ volume (DUNCAN et al., 2000; WONG et al., 2000).

Stape et al. (2004), ao estudarem Eucalyptus grandis x E. urophylla, observaram que a irrigação aumentou a produtividade em biomassa do caule em $52 \%$. Gentil
(2010) encontrou incremento em biomassa de $62 \%$ em parcelas irrigadas de eucalipto, em comparação com as parcelas não irrigadas.

Com relação à redução linear da condutância estomática (gs) com o aumento do déficit de pressão de vapor na área úmida (Figura 3A), Lima et al. (2003) também observaram queda linear da condutância estomática em função do aumento do déficit de pressão de vapor em Eucalyptus.

Os quatro clones apresentaram queda de aproximadamente $0,16 \mathrm{~mol} \mathrm{~m} \mathrm{~m}^{2} \mathrm{~s}^{1}$ na condutância estomática para cada $1 \mathrm{kPa}$ de aumento no DPV. Além disso, os clones se assemelharam quanto ao DPV limite para o completo fechamento estomático, que se situa entre 2,8 e 3,2 kPa. Mielke (1997) e Marrichi (2009) encontraram valores de DPV limites superiores aos encontrados neste estudo, entre 3,5 e 4,5 kPa.

Na área de clima seco, não houve relação entre condutância estomática e déficit de pressão de vapor (Figura 3B). Em função da baixa umidade do solo, as plantas da área seca mantiveram seus estômatos praticamente fechados. Johnson e Ferrel (1983) observaram que a resposta dos estômatos ao DPV é reduzida em solos secos, comparados a solos úmidos. Vellini et al. (2008) constataram redução da condutância estomática e da transpiração, em clones de eucalipto, com a redução da disponibilidade de água. Essa restrição

Revista Árvore, Viçosa-MG, v.36, v.37, n.3, p.431-439, 2013 
da perda de água através do fechamento dos estômatos e o aumento da aquisição da água pelo sistema radicular são mecanismos importantes para a sobrevivência das plantas em situações de déficit hídrico (NGUGI et al., 2004).

As taxas fotossintéticas de 12,5 a $16,4 \mu \mathrm{mol} \mathrm{m} \mathrm{m}^{2} \mathrm{~s}^{-1}$ encontradas na área úmida são valores inferiores ao valor encontrado por Tatagiba et al. (2007), em que a fotossíntese máxima foi de $24 \mu \mathrm{mol} \mathrm{m} \mathrm{m}^{2} \mathrm{~s}^{-1}$ para clones de eucalipto em uma época chuvosa. Marrichi (2009)

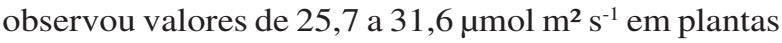
de eucalipto aos 16 meses de idade. White Head e Beadle (2004) encontraram valores da ordem de 13 a $32 \mu \mathrm{mol} \mathrm{m} \mathrm{m}^{2} \mathrm{~s}^{-1}$ para 11 espécies de Eucalyptus.

Já as taxas de fotossíntese encontradas na área de clima seco são valores inferiores aos obtidos no trabalho realizado por Macfarlane et al. (2004), que encontraram valores para $E$. globulus variando de 5 a $10 \mu \mathrm{mol} \mathrm{m} \mathrm{m}^{2} \mathrm{~s}^{-1} \mathrm{em}$ uma época com déficit hídrico.

A relação linear entre a fotossíntese máxima e a produtividade dos clones (Figura 4) explica a maior produtividade da área úmida. Segundo Kirschbaum (2011), cerca de $30 \%$ do aumento na taxa fotossintética resulta em aumento de $10 \%$ no crescimento das plantas. No entanto, a taxa fotossintética não explicou a diferença do volume obtido entre os clones da área úmida, uma vez que o clone que apresentou maior taxa fotossintética (clone A) obteve o menor volume (Tabela 1). Isso pode ser elucidado, ao menos em parte, pelo fato de a avaliação de crescimento ser resultante de um processo contínuo que resulta no acúmulo de biomassa, enquanto a avaliação de fotossíntese é realizada em uma ocasião pontual durante o crescimento da planta.

Marrichi (2009) não encontrou relação entre crescimento das árvores de eucalipto e as taxas fotossintéticas, mostrando que nem sempre os processos estudados em nível de folha isoladamente são suficientes para explicar a produtividade das árvores. Dessa forma, a relação entre fotossíntese e produtividade pode apresentar resultados diferentes entre as espécies ou clones estudados, uma vez que a maior produtividade pode estar relacionada à maior área foliar, ao próprio potencial fotossintético e à eficiência do uso da luz (INOUE; RIBEIRO, 1988; RYAN et al., 2010).

Este trabalho apresentou resultados de crescimento e avaliações fisiológicas de clones de Eucalyptus submetidos a diferentes condições edafoclimáticas em uma região de franca expansão em área de cultivo dessa espécie, na Região Nordeste do Brasil. Os resultados apresentados evidenciaram taxas de fotossíntese muito mais baixas na área seca do que na área úmida, o que certamente está relacionado à redução drástica no crescimento do eucalipto na área de maior déficit hídrico. O estudo apresenta, portanto, informações úteis que dão subsídio ao entendimento da redução do crescimento do eucalipto à medida que os plantios avançam para áreas mais sujeitas ao déficit hídrico. Isso se torna mais importante nos dias atuais, em que o aumento da competição por terras agricultáveis no Brasil levou à expansão da cultura para áreas marginais .

O entendimento dos fatores que influenciam as respostas fisiológicas dos plantios de eucalipto pode, dessa forma, ajudar no planejamento e localização dos plantios e na seleção de genótipos, bem como na escolha do manejo adequado para plantios instalados em ambientes com restrições hídricas. Além disso, a obtenção de dados sobre a capacidade fotossintética das plantas é uma importante ferramenta para modelos baseados em processos que necessitam de informações fisiológicas para a predição do crescimento e uso da água de diferentes genótipos.

\section{CONCLUSÕES}

Com as medições de fotossíntese e condutância estomática, foi possível entender o efeito da disponibilidade hídrica no crescimento dos plantios de eucalipto. $\mathrm{Na}$ área seca, o déficit hídrico foi um fator limitante para a abertura estomática e contribuiu para a queda na assimilação de carbono pela fotossíntese. Ao contrário da área úmida, que, além de apresentar controle estomático em função do déficit de pressão de vapor, apresentou maiores valores das taxas fotossintéticas e produtividade.

No entanto, diante dos resultados não foi possível diferenciar os clones através da relação entre produtividade e fotossíntese, indicando que medições pontuais dessa variável e da condutância estomática não são suficientes e, portanto, devem ser avaliadas em diferentes idades da floresta, abrangendo distintas condições climáticas.

\section{AGRADECIMENTOS}

À empresa Veracel Celulose S/A, pela disponibilidade e concessão das áreas experimentais ultilizadas neste estudo; e ao Grupo Florestal Monte Olimpo, pelo apoio na coleta e processamento dos dados. 


\section{REFERÊNCIAS}

ABRAF. Anuário estatístico da ABRAF 2011 ano base 2010 /ABRAF - Brasília:2011. 130p.

ADDINGTON, R. N. et al.Stomatal sensitivity to vapor pressure deficit and its relationship to hydraulic conductance in Pinuspalustris. Tree Physiology, v.24, n.5, p. 561-569, 2004.

DUNCAN, M. J. et al. Growth of eucalypt plantation species across twelve sites in Gippsland. Victoria: Department of Natural Resources and Environment, 2000.

FLOSS, E. L. Fisiologia das plantas cultivadas. Passo Fundo: 2004. 536p.

GENTIL, M. S. Transpiração e eficiência do uso da água em árvores clonais de Eucalyptus aos 4 anos em áreas com e sem irrigação em Eunápolis, Bahia. 2010. 71f. Dissertação (Mestrado em Recursos Florestais) - Escola Superior de Agricultura "Luiz de Queiroz", Universidade de São Paulo, Piracicaba, 2010.

GRANIER, C.; TARDIEU, F. Spatial and temporal analyses of expansion and cell cycle in sunflower leaves. A common pattern of development for all zones of a leaf and different leaves of a plant. Plant Physiology, v.116, n.3, p.991-1001, 1998.

HUAMAN, C.A.M.Impacto do estresse abiótico em plantas no contexto das mudanças climáticas. 2010. 62f. Tese (Livre Docência) - Universidade de São Paulo, Ribeirão Preto, 2010.

INOUE, M. T.; GALVÃO, F.; TORRES, D.V.Estudo ecofisiológico sobre Araucariaangustifolia: Fotossíntese em dependência à luz no estágio juvenil. Revista Floresta, v.10, n.1, p.5-9, 1979.

INOUE, M. T.; RIBEIRO, F.A. Fotossíntese e transpiração de clones de Eucalyptus grandis e E. saligna.IPEF, n.40, p.15-20, 1988.

JOHNSON, J. D.; FERRELL, W. K. Stomatal response to vapour pressure deficit and the effect of plant water stress. Plant, Celland

Environment, v.6, n.3, p.451-456, 1983.
KAGEYAMA, P. Y. Variação genética em progênies de uma população de Eucalyptus grandis (Hill) Maiden. 1980. 125f. Tese (Doutorado em Genética e Melhoramento de Plantas)Escola Superior de Agricultura "Luiz de Queiroz", Universidade de São Paulo, Piracicaba, 1980.

KIRSCHBAUM, M. U. F. Does enhanced photosynthesis enhance growth? Lessons learned from $\mathrm{CO}_{2}$ enrichment studies, Plant

Physiology, v.155, n.1, p.117-124, 2011.

KÖPPEN, W.; GEIGER, R. Klimate der Erde. Gotha: Verlag Justus Perthes. Wall-map $150 \mathrm{~cm} x 200 \mathrm{~cm}, 1928$.

LARCHEVEQUE, M. et al. How does drought tolerance compare between two improved hybrids of balsam poplar and an unimproved native species? Tree Physiology, v.31, n.3, p.240-249, 2011.

LIMA, W. P.; JARVIS, P.; RHIZOPOULOU,S. Stomatal responses of Eucalyptus species to elevated $\mathrm{CO}_{2}$ concentration and drought stress. Scientia Agricola, v.60, n.2, p.231-238, 2003.

MACFARLANE, C.; WHITE, D. A.; ADAMS, M. A. The apparent feed-forward response to vapour pressure deficit of stomata in droughted, field-grown Eucalyptus globulusLabill. Plant, Celland Environment, v.27, n.10, p.12661280, 2004.

MARRICHI, A. H. C. Caracterização da capacidade fotossintética e da condutância estomática em sete clones comerciais de Eucalyptuse seus padrões de resposta ao déficit de pressão de vapor. 2009. 104f. Dissertação (Mestrado em Recursos Florestais) - Escola Superior de Agricultura "Luiz de Queiroz", Universidade de São Paulo, Piracicaba, 2009.

MEDIAVILLA, S.; ESCUDEIRO, A.Stomatal responses to drought of mature trees and seedlings of two co-occurring Mediterranean oaks. Forest Ecology and Management, v.187, n.2-3, p.281-294, 2004.

MIELKE, M. S. Regulação fisiológica e ambiental das trocas gasosas num plantio clonal de Eucalyptusgrandis Hill ex-Maiden. 92f. Tese (Doutorado em Fisiologia Vegetal) - Universidade Federal de Viçosa, Viçosa, MG, 1997. 
MORRIS, J.; BENYON, R. Plantation water use. New Forests: wood production and environmental services. Collingwood: 2005. p.75-104.

NGUGI, M. R. et al. Selection of species and provenances for low-rainfall areas: physiological responses of Eucalyptuscloeziana and Eucalyptus argophloia to seasonal conditions in subtropical Queensland. Forest Ecologyand

Management, v.193, n.1-2, p.141-156, 2004.

ROLIM, G. S.; SENTELHAS, P. C.; BARBIERI, V. Planilhas no ambiente EXCEL ${ }^{\mathrm{TM}}$ para os cálculos de balanços hídricos: normal, sequencial, de cultura e de produtividade real e potencial.

Revista Brasileira de

Agrometeorologia, v.6, n.1, p.133-137, 1998.

RYAN, M. G. et al. Factors controlling Eucalyptus productivity: how water availability and stand structure alter production and carbon allocation. Forest Ecology and Management, v.259, n.9, p.1695-1703, 2010.

RYAN, M. G. Tree responses to drought. Tree Physiology, v.31, n.3, p.237-239, 2011.

SETTE JR, C. R. et al.Crescimento em diâmetro do tronco das árvores deEucalyptusgrandis W. Hill. ex. Maiden e relação com as variáveis climáticas e fertilização mineral. Revista Árvore, v.34, n.6, p.979-990, 2010.

STAPE, J. L. et al. Water use, water limitation and water use efficiency in a Eucalyptus plantation. Bosque, v.25, n.1, p.35-41, 2004.
TATAGIBA, S. D.; MONTAGU, K. D.; CONROY, J.P. Temperature effects on wood anatomy, wood density, photosynthesis and biomass partitioning of Eucalyptus grandisseedligs. Tree Physiology, v.27, n.2, p.251-260, 2007.

THORTHWAite, C. W.; MATTER, J. R. The water balance. publications in climatology, New Jersey: Drexel Institute of Thecnology, 1955.104p.

VELLINI, A.L.T.T. et al.Respostas fisiológicas de diferentes clones de eucalipto sob diferentes regimes de irrigação, Revista Árvore, v.32, n.4, p.651-663, 2008.

WHITEHEAD, D.; BEADLE, C. L.

Physiological regulation of productivity and water use in Eucalyptus: a review. Forest

Ecology and Management, v.193, n.1-2, p.113-140, 2004.

WONG, J. et al. Forecasting growth of key agroforestry species in south-eastern Australia.Canberra: Rural Industries Research and Development Corporation, 2000.RIRC (Publication 00/68).

WOOLHOUSE, H. W. The biochemistry and regulation of senescence in chloroplasts. Canadian Journal of Botany, v.62, n.12, p.2934-3942, 1984. 
